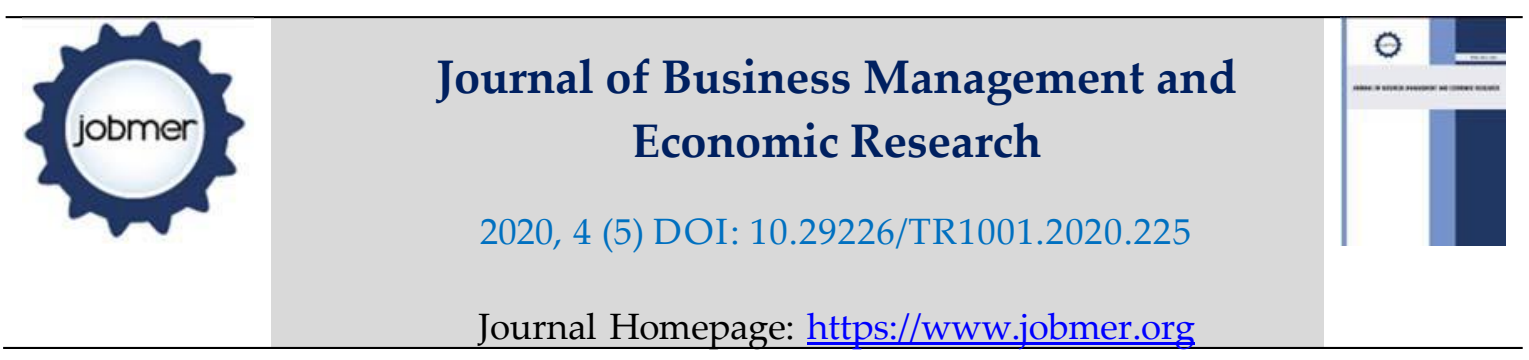

\title{
Inventory Categorization and Operational Performance: A Supply Chain Analysis of Public Hospitals in Kenya
}

\author{
Okello, Sharone Adhiambo
}

School of Business \& Economics

Jaramogi Oginga Odinga University of Science and Technology

Arani, Wycliffe

School of Business \& Economics

Jaramogi Oginga Odinga University of Science and Technology

\section{Sitienei, Carolyne Koech}

School of Business \& Economics

Jaramogi Oginga Odinga University of Science and Technology

\begin{abstract}
Performance of public hospitals is becoming a major concern to Kenyans. Public hospitals are currently facing the problem of balancing between overstocking and understocking of drugs. The main objective of this study was to determine the effect of inventory categorization practices on operational performance of public hospitals in Siaya County, Kenya. This study was anchored on Resource Based View Theory and Network Perspective Theory. The study adopted cross- sectional survey research design. The target population of the study was 106 with a sample size of 84 based on Yamane formula. The study adopted stratified proportionate and simple random sampling. Structured questionnaires and interview guides to collect primary data. Reliability was tested using split half analysis while validity was tested using expert judgement at an index of 0.70 Cronbach's Alpha coefficient. Descriptive statistics were analyzed using frequency percentage, mean and standard deviation. Inferential statistics were analyzed using regression and correlation analysis. The hypothesis that, "there is no significant statistical effect of inventory categorization practice on operational performance of public hospitals in Siaya County" was rejected based on the findings which showed that inventory categorization had a statistically significant effect on performance of public hospitals in Siaya County with a coefficient of $\beta=.754$. The study concluded that the efforts that public hospitals put in inventory categorization as an inventory management practice would eventually become critical in realizing an improved operational performance in terms of service delivery for the patients. The study recommends that inventory Managers should categorize inventory with accurate forecasts.
\end{abstract}

Key Words: Inventory, Inventory Categorization, Operational Efficiency, Operational Performance

\section{Suggested Citation:}

Okello, S. O., Arani, W. \& Sitienei, C. K., (2020). Inventory Categorization and Operational Performance: A Supply Chain Analysis of Public Hospitals in Kenya. Journal of Business Management and Economic Research (JOBMER), Vol: 4, Issue: 5, 


\section{Introduction}

Globally, all public and private hospitals are known to be keen on their performance in terms of operational efficiency and service delivery (Isaksson and Seitfert, 2013). Public hospitals are obligated to provide 24-hour services thus the need to maintain sufficient medical inventory to be able to discharge their duties effectively. It is a generally held opinion that where stock management by public hospitals is poor, delivery of healthcare is normally affected (Stevenson, 2010). In Kenya, public hospitals are currently facing the problem of determining appropriate inventory levels that should be kept ensuring patients' needs are met (Wafula, 2016). As such, the act to strike a balance between overstocking and understocking is one of their major challenges in public hospitals and subsequently operational performance is often an issue (Isaksson and Seitfert, 2013). According to a report by the Ministry of Health $(\mathrm{MoH})$ in March 2018, sixty percent of mortality rates in Siaya are attributed to unavailability of drugs if not untimely administration of drugs. Patients, for instance, are more likely to die prematurely out of malaria and tuberculosis in Siaya due to unavailability of drugs. A study conducted by Oboge (2017), revealed that public hospitals in Siaya County suffered from lack of critical items like drugs. In a research conducted by the ministry of health in 2018, different people from Siaya County shared their frustration stories of not being able to find drugs in the health facilities leaving them with the only option of purchasing from chemists, where prices are perceived to be high. Sixty percent of patients that were advised to purchase drugs from chemists ended up not doing so and waited upon fate to take action. This study therefore sought to establish the effect of inventory management practices on operational performance of public hospitals in Siaya County.

Davis et al (2003) defines inventory as "the stock of any item or resource used in an organization". In a broader context, inventory includes physical items such as raw material; inputs such as parts, components, and finished goods; and interim stages of the process, such as partially finished goods or work-in-progress. Coyle et al (2003) defines inventory as "raw materials, work- in- progress, finished goods and supplies required for creation of a company's goods and services". According to Miller (2010), inventory management involves all activities put in place to ensure that customer have the needed product or service at the right time and in the right place including but not limited to inventory categorization.

Dinesh \& Choudary, (2003) defined inventory categorization as the putting of inventory into various groups or classes according their importance of their relative value. Pareto (1923) defines inventory categorization as the putting of inventory items into various categories according to some preset criterion such as revenue generation, turnover, or value. On the other hand, Neely, (2005) defines operational performance as the performance of an organization against prescribed standards such as compliance with regulation, waste reduction, and productivity. Neely, (2005) adds that, it is the firms' performance measured against standard or prescribed indicators of efficiency, effectiveness and regulatory compliance. It is understood to be a set of standards used to quantify both the efficiency and effectiveness of actions (Neely, 2005). Measurements of operational performance are outlined by Neely, (2005) as efficiency, effectiveness, quality, timeliness, flexibility, cost and productivity. Birech (2011) outlines various performance metrics within operations set up as productivity measures, quality measures, inventory measures and cost of quality.

Kaplan and Norton (1992), suggest measuring an organization's performance around four perspectives: (1) financial, (2) customer, (3) internal processes, and (4) learning and growth. This framework provides a balance between short- and long-term objectives, financial and non-financial 
measures, and external and internal performance indicators. According to Stevenson, (2009), there are two main concerns about performance attributed to inventory management practices. First, performance attributed to inventory management practices concerns the level of customer service, that is, to have the right goods in sufficient quantities, in the right place and at the right time. Another concern is the cost of ordering and carrying inventories. Measuring service quality is one of the most important activities to improve perceived service quality, make a difference, gain competitive advantage, and sustain profit levels of the hospitals. As a result, the measurement of service quality deserves special attention (Baki et al, 2009). Gefen (2002) adds that it is a comparison made by the customers between the quality of services they want to receive and what they actually received from the service provider.

According to Asubonteng et al. (1996), Service quality can be defined as "the difference between customers"expectations for service performance prior to the service encounter and their perceptions of the service received." The firm's operational performance is calculated in relation to standard or prescribed indicators of effectiveness, efficiency and environmental responsibility, such as cycle time, productivity, waste reduction, and regulatory compliance as indicated by Salami and Adayami (2010). In order to improve operational efficiency an organization has to measure both the input and the output side of the inventory management (Abdel-Maksoud et al, 2008). Efficiency is a function of input, process and output. In public hospitals, operational efficiency generally refers to attending to averagely more patients in less time therefore saving more lives. This involves being very precise in diagnosis with a proper coordination links to other departments leading to easier time for patients going through the treatment process. Efficiency can be measured in consideration to the number of admissions and discharges for in patients, average length of stay for outpatients, mortality statistics and opinions from the suggestion box. Njoroge (2015) looked at operational performance of public hospitals in terms of availability of drugs and infrastructural facilities, timely delivery, cost reduction, reduced lead time, supplier reliability, reduced stock out cost, customer service delivery and reduced waste. Karanja and Mbugua (2018) viewed operational performance of private hospitals in terms of waste reduction, efficiency and effectiveness, employee, and customer's satisfaction. Oballa et al, (2018) considered organizational performance as cost reduction and customer satisfaction. The goal of operations is to run efficiently, provide consistent, high-quality services, and continually improve the customer experience. This study adopted Operational efficiency and service delivery as the indicators for operational performance.

The study was anchored on two theories to inform the variables underlined. These theories include Resource-Based View Theory and Network Perspective Theory. The Resource-Based View (RBV) was developed by Edith Penrose (1959). She looked at an organization as a collection of tangible and intangible resources bound together in an organizational structure. The theory regards the firm as a collection of resources and capabilities that together enhance performance (Wernerfelt, 1984). The RBV theory examines the impact of organization resources and capabilities on competitive advantage that leads to overall organizational performance. Based on Ray et al, (2004) study, the resources and capabilities that are not conditioned into sustaining activities and business processes would not have positive impact on an organizational performance.

Resource Based View has a limitation in that it focuses on the internal organization and does not put in consideration the ever-changing external environment. This imply that even if a firm has the capabilities to gain competitive advantage, the external environment might not be favorable to support achievement of competitive advantage (Barney and Clark, 2014). This theory is relevant to this study since the performance of hospitals greatly depend on management of drugs, which is 
linked to the coordination of different parties involved in the entire supply chain. In view of this, the theory would inform the independent variables.

Network Perspective Theory was accredited to Jacob Moreno (1930) who first developed sociograms in the 1930s in an attempt to study interpersonal relationships. Network perspective theory appreciates the social set of actors who are commonly referred to as nodes and how they relate to each other in forms of ties or edges (Wasserman \& Faust, 2014). The nodes may be individuals, groups or organization. The network perspective theory involves communication ties (such as who talks to whom, or who gives information or advice to whom), formal ties (such as who reports to whom), affective ties (such as who likes who, or who trusts who), material or work flow ties (such as who gives money or other resources to who), proximity ties (who is spatially or electronically close to who), and cognitive ties (such as who knows who). The theory generally outlines the relationship among employees in the organization (Katz et al, 2014). Networking perspective theory enables an organization to have social networks with all parties involved in the success of an organization. An organization operates in a social setting and thus an open system with different players who operate in a unique set up that enables it to achieve its objectives

Major limitation of network perspective theory is that despite its profound ability to enable organizations in knowledge sharing, it is unclear how the relationships are being created. The theory is seen to be focusing on big companies with many employees and extended parties. On the other hand, it is also possible that some aspects of knowledge sharing are just simply not detected through the network (Bosua \& Scheepers, 2007). The theory was relevant to this study because it would inform the moderating variable. All the parties involved in inventory management of public hospitals have a social link that enable them work together with a common interest to ensure an efficient inventory supply chain.

According to Vipulesh (2015), proper inventory classification improves the level of customer service, which in turn improves financial performance; this was established in his research, which sought to establish the impact of inventory categorization on the financial performance of manufacturing firms in India. The study focused on secondary data from journals, articles, magazines and preferred books from library. The study adopted descriptive research design. Data was interpreted by correlation techniques. The study recommended that manufacturing firms should install optimal inventory classification techniques or improve their asset turn over as much as possible. This study entirely relied on secondary data only. The study focused on financial performance and this study therefore seeks to divert and look into the operational performance.

Yazan (2017) conducted a study on the relationship between inventory categorization and operational excellence in Jordan, Asia. The study focused on manufacturing companies. The study found out that inventory categorization has a positive impact on operational excellence on Jordanian Industrial factories. The study goes ahead to state that categorizing inventory is currently considered as a backbone and a critical pillar for many companies who strive to achieve competitive advantage through operation. The study recommended that same study could be carried out in other sectors such as food industry and pharmaceutical industries in order to generalize the results. This study therefore sought to find out the effect of inventory categorization practices on operational performance of public hospitals.

John et al, (2015) conducted a study on inventory categorization and operational performance of flour milling manufacturing firms in Lagos Nigeria. The study intended to find out the inventory categorization practices being used and to establish whether there existed a significant relationship 
between the practices and operational performance. Descriptive research design was adopted. Structured questionnaires were used to collect primary data. Data was analyzed by inferential statistics. The study established that most of the flour milling firms that adopted scientific inventory categorization practices experienced increased operational performance as compared to those that employed manual practices. The study however did not use a moderating variable while establishing the relationship between inventory categorization practices and operational performance. This study seeks to establish the relationship between inventory categorization practices and operational performance with a moderating variable in between.

A study conducted by Suleman 2018 in Ghana revealed that there existed no positive relationship between inventory categorization and performance of manufacturing firms under study. The study aimed to investigate the impact of inventory categorization on the performance of selected manufacturing firms in Ghana. The study used cross sectional survey design with secondary data. Pearson correlation and regression analysis were used to analyze data. In the findings, the performance of manufacturing firms under study did not depend on categorizing raw materials. This study sought to find out the effect of inventory categorization practices on operational performance of public hospitals.

John (2016) conducted a study, which sought to assess the relationship between inventory categorization and the effectiveness of the downward supply chain of essential medicines in the public hospitals in Uganda. The study adopted a cross sectional research design. Both qualitative and quantitative data was collected. Data was interpreted by correlation analysis. The study found a significant relationship between inventory categorization and the downward supply chain off essential medicines. Even though the study found a significant relationship, correlation analysis only is not significant enough to give a clear picture on the relationship between two variables. This study therefore sought to adopt both correlation and regression analysis in analysis data to ascertain the existence of a significant relationship between inventory categorization and operational performance of public hospitals in Siaya county.

Mwajuma 2013 conducted a study which sought to assess the effectiveness of inventory control systems in the public sector in Tanzania; a case of Kilwa District Hospital. The study intended to assess the effectiveness of $\mathrm{ABC}$ analysis in inventory control and the performance of the Hospital. The study adopted case study research design. Both primary and secondary data was collected through interview and questionnaire. The study adopted purposive sampling method and data was analyzed by descriptive statistics. The findings indicated that ABC analysis used as an inventory control method had positive impact on the performance of the hospital.

Wafula (2016), in his study on effect of inventory categorization on operational performance of oil marketing companies in Kenya, sought to establish the effect of inventory categorization on operational performance. The study employed descriptive research design and census sampling technique on 75 oil-marketing companies in Kenya. Interview guide collected data. The study revealed that the use of $\mathrm{ABC}$ analysis in categorizing inventory have a positive increase on operational performance of the companies under study. Data was analysed by descriptive statistics. The research concluded that inventory management is a continuous process therefore an organization should strive to manage their inventory through favorable categorization practices to reap good performance hence competitive advantage. Even though the researcher analyzed data by use of descriptive statistics, this alone is not sufficient to give a clear picture on the relationship between the variables. This study therefore seeks to add correlation and regression on top of 
descriptive in analyzing the relationship between inventory categorization and operational performance of public hospitals in Siaya County.

Njoroge (2015) conducted a study on inventory management practices and performance of public hospitals in Nairobi, Kenya. The study sought to determine the inventory management practices used in public hospitals, establish the relationship between inventory management practices used and performance of public hospitals, and determine the challenges of implementing inventory management practices in public hospitals. The study adopted correlation research design with purposive sampling. Data was interpreted by inferential statistics. The study found out that most popular inventory management practices used were ERP systems, ABC and EOQ models. The study also found out that the main challenge of implementation was failure to invest in modern technologies, lack of top management training and unreliable suppliers. The study concluded that inventory management practices are positively related to the performance of public hospitals. The researcher recommended same study to be conducted in other counties to determine if result was consistent. This study therefore sought to establish the effect of inventory categorization practices on operational performance of public hospitals in Siaya County

The Kenya Health Policy (2014-2030) indicates that the government under the Ministry of Health works closely with public hospitals to ensure that goods and services are delivered on time in order to provide quality health care services to the citizens. According to the Kenya Constitution (2010), the Mandate of the Ministry of Health is to formulate policies, set standards, provide health services, create an enabling environment and regulate the provision of health service delivery. The County Government is responsible for County health services, pharmacies, and ambulance services, promotion of primary health care, licensing and control of undertakings that sell food to public, cemeteries, funeral parlors and waste disposal. Kenya's healthcare is provided by Public and privateowned hospitals. The public sector includes National Referral Hospitals, county referral Hospitals, Sub-County Hospitals, Health Centers and Dispensaries. National Referral hospitals usually have full complement of medical services such as surgery, pediatrics, obstetrics, general medicine and gynecology. Patients are often referred to National referral hospitals when the situation is more complex for county referral hospitals to manage. County Referrals, intermediate between national referrals and the sub county level. They oversee the implementation of health policy at the sub county level, maintain quality standards, and coordinate and control all health activities. Sub county hospitals concentrate on the delivery of health care services. Health center and dispensaries provide preventive and curative services. (Ministry of Health in Kenya, website)

Sub-County Hospitals independently prepares an annual procurement plan for specific financial year, which is then forwarded to the County Health Director. The county procurement officer then consolidates the procurement plans for the whole county. Major supplies are directed to KEMSA while minor ones can be purchased through Request for quotation. Even though the county procurement officer is mandated to do all the purchases for County hospitals, when need arises, the sub county hospitals can purchase from local vendors through request for quotation. (County Health Director, Siaya Kenya). Kenya Medical Supplies Authority (KEMSA) supplies drugs to the County governments who then does the distribution to all public hospitals under respective counties. Kenya is currently experiencing increase in diabetes, heart diseases, cancer, chronic lungs, neurological, psychiatric diseases and unexpected injuries more than communicable diseases like malaria, HIV and tuberculosis resulting into double financial burden for the Government (Yonga, 2018). With the increasing health burden, the performance of public hospitals is becoming a major concern to the people of Kenya. According to Kenya National Bureau of Statistics study (2018), 45.2\% of Kenya's 
population are living in poverty and access to basic quality health care is a luxury to them, so the only option is to seek refuge in public hospitals where charges are generally fair.

Even though affordable healthcare is one of the big four agenda that Kenya aims to achieve by 2022, something must be done between now and then especially in public hospitals to ensure Kenyans get better services when it comes to drugs availability. According to a report by the ministry of health (2018), different people shared their frustration stories of the pain of buying drugs from chemist every time they visited public hospitals within Siaya County. There is need for hospitals to maintain smooth supply of drugs to ensure uninterrupted service delivery, for this to be achieved it calls for proper inventory management of pharmacy stock by keeping an accurate track. Siaya County in collaboration with World Health Organization has invested heavily in-service delivery, health leadership and governance, human resources for health, health infrastructure and equipment and health information systems (Siaya County web site). However, it is surprising that among the plans that the County government of Siaya has for health sector, inventory management is not amongst them. According to a report by Ministry of Health 2018, Siaya County has the highest mortality rate and its residents were much likely to die prematurely than residents of other counties. HIV/AIDS and malaria were the major causes of death as reported by the ministry of health in which unavailability of drugs was pointed out to be the major factor leading to deaths related to malaria.

\section{Statement of the Problem}

Public hospitals are obligated to provide 24-hour services thus the need to maintain sufficient medical inventory to be able to discharge their duties effectively. It is a generally held opinion that where stock management by public hospitals is poor, delivery of healthcare is normally affected, Njoroge (2015). Public hospitals are facing the problem of determining appropriate inventory levels that should be kept ensuring patients' needs are met. Striking balance between overstocking and understocking is one of their major challenges (Hani et al 2013). A study conducted by Oboge (2017), revealed that public hospitals in Siaya County suffered from lack of critical items like drugs. In a research conducted by the ministry of health in 2018, different people from Siaya County shared their frustration stories of not being able to find drugs in the health facilities leaving them with the only option of purchasing from chemists, where prices are perceived to be high. Sixty percent $(60 \%)$ of patients that were advised to purchase drugs from chemists ended up not doing so and waited upon fate to act.

Being along Lake Victoria, Siaya is considered having high prevalence to HIV/AIDS and malaria infections compared to other regions (ministry of health and Kenya Open Data). According to a report by the Ministry of health in March 2018, Siaya County has the highest mortality rate and study revealed that its residents were much likely to die prematurely out of malaria and HIV/aids. Malaria related deaths were linked to unavailability of drugs in public facilities. Even though past studies reported that public hospitals in Siaya County have in place the inventory management practices under study, their service delivery is considered poor by the public. Based on that, this study therefore sought to determine the effect of inventory management practices on operational performance of public hospitals in Siaya County. This study thus sought to establish the effect of inventory categorization on operational performance of public hospitals in Siaya County. 


\section{Methodology \\ Research Design}

The study adopted cross sectional survey research design. A cross sectional survey research is a process of collecting data in order to answer questions concerning the current status of the subjects in the study (Cooper \& Schindler, 2014). The study considers this design appropriate since it would facilitate the gathering of reliable data that would give a true picture of the current problem by looking across the public hospitals in Siaya County. Cross Sectional Survey would also be used since it is an excellent vehicle for collection of original data for studying the attitudes and orientations of a large population using only a portion of that population to provide the required data. This would help the study to establish the effect of inventory management practices on operational performance of public hospitals in Siaya County.

\section{Area of study}

Siaya is one of the 47 counties in Kenya, located in Nyanza province. There are six sub-counties in Siaya County, namely Ugenya, Ugunja, Gem, Bondo, Rarieda and Alego-Usonga. The researcher chose on Siaya County since it was ranked the leading County in mortality rates in Kenya and its residents were said to be at risk of premature deaths due to high prevalence in HIV/AID and malaria (Ministry of Health 2018). It was also ranked the second after Homabay County in HIV/AIDS prevalence (WHO 2017), hence the need for adequate supply of medicines amongst other requirements.

\section{Target Population of the Study}

The target population of the study was 106 comprising all the staff working in the procurement, stores, pharmacy and administration across the six (6) sub county hospitals in Siaya County; Sigomere Sub-County Hospital, Bondo sub-County hospital, Malanya Sub-County Hospital, Yala Sub-County Hospital, Madiany Sub-County Hospital and Siaya County Referral Hospital. The population would therefore be made up of 34 administrators, 33 pharmacists, 18 procurement staff and 21 storekeepers. Therefore, the target population of 106 was distributed as shown in Table 1.

Table 1. Target Population

\begin{tabular}{rlccccccc}
\hline & $\begin{array}{c}\text { Ungenya } \\
\text { (Sigomere } \\
\text { Sub- } \\
\text { County } \\
\text { Hospital) }\end{array}$ & $\begin{array}{c}\text { Ugunja } \\
\text { (Malanya } \\
\text { Sub- } \\
\text { County } \\
\text { Hospital) }\end{array}$ & $\begin{array}{c}\text { Gem } \\
\text { (Yala } \\
\text { Sub- } \\
\text { County } \\
\text { Hospital) }\end{array}$ & $\begin{array}{c}\text { Bondo } \\
\text { (Bondo } \\
\text { Sub- } \\
\text { County } \\
\text { Hospital) }\end{array}$ & $\begin{array}{c}\text { Rarieda } \\
\text { (Madiany } \\
\text { Sub- } \\
\text { County } \\
\text { Hospital) }\end{array}$ & $\begin{array}{c}\text { Alego- } \\
\text { Usonga } \\
\text { (Siaya } \\
\text { County } \\
\text { Referral } \\
\text { Hospital) }\end{array}$ & Total \\
\hline 1. Administration & 05 & 05 & 05 & 05 & 05 & 09 & 34 \\
2. Pharmacy & 06 & 04 & 03 & 05 & 04 & 11 & 33 \\
3. Procurement & 03 & 03 & 02 & 03 & 02 & 05 & 18 \\
4. Stores & 03 & 03 & 03 & 03 & 03 & 06 & 21 \\
\hline Total & & & & & & & & $\mathbf{1 0 6}$ \\
\hline
\end{tabular}

Source: Siaya County MoH, (2018) 


\section{Sample Size and Sampling Procedure}

The section aims at establishing the sample size of the study respondents and how sampling was done. It is discussed as follows:

\subsubsection{Sample Size}

The sample size is a representative of a large population (Bryman, 2012). Yamane, (1967) formula was used in determining the sample size. The sample size in each stratum was obtained proportionately. In the field the respondents were selected using random sampling.

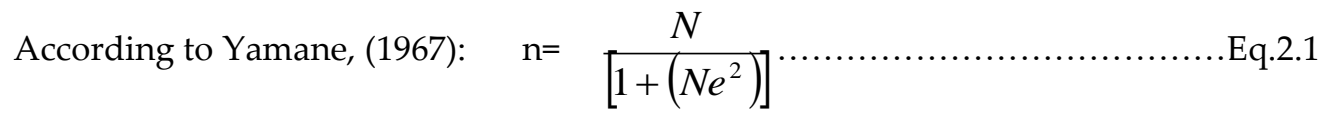

Where

$$
\begin{aligned}
& \mathrm{n}=\text { is the sample size } \\
& \mathrm{N}=\text { is the population } \\
& \mathrm{e}=\text { is the error limit ( } 0.05 \text { on the basis of } 95 \% \text { confidence level) }
\end{aligned}
$$

Therefore,

$$
\begin{gathered}
\mathrm{n}=106 /\left[1+106(0.05)^{2}\right] \\
\mathrm{n}=106 / 1.265 \\
\mathrm{n}=84
\end{gathered}
$$

Using a population of 106 staff members in public hospitals in Siaya County and considering an error limit of $5 \%$, a sample size of 84 was used in the study. This sample size was representative enough and was spread in each stratum proportionately as illustrated in Table 2.

Table 2. Sample Frame

\begin{tabular}{lcccccccc}
\hline & $\begin{array}{c}\text { Population } \\
\text { S(X) }\end{array}$ & $\begin{array}{c}\text { Sample Sigomere Malanya Yala Bondo Madiany } \\
\text { Size } \\
\mathbf{X} / \mathbf{N ~} \mathbf{x} \\
\mathbf{8 4}\end{array}$ & & & & & $\begin{array}{c}\text { Siaya } \\
\text { County } \\
\text { Referral } \\
\text { Hospital) }\end{array}$ \\
\hline 1. Administration & 34 & 27 & 4 & 4 & 4 & 4 & 4 & 7 \\
2. Pharmacy & 33 & 26 & 5 & 3 & 2 & 4 & 3 & 9 \\
3. Procurement & 18 & 14 & 2 & 2 & 2 & 2 & 2 & 4 \\
4. Stores & 21 & 17 & 2 & 2 & 2 & 3 & 3 & 5 \\
\hline Total & $\mathbf{1 0 6}$ & $\mathbf{8 4}$ & $\mathbf{1 3}$ & $\mathbf{1 1}$ & $\mathbf{1 0}$ & $\mathbf{1 3}$ & $\mathbf{1 2}$ & $\mathbf{2 5}$ \\
\hline
\end{tabular}

Source: Researcher's own conceptualization, (2018)

\section{Sampling Procedure}

In view of the researcher's inability to reach out to the entire population, and in order to gain the advantage of an in-depth study and effective coverage, Yamane formula was used to establish the sample size from the study population. Stratified proportionate sampling was used to get sample size for each stratum. In the field, respondents were selected using simple random sampling. 


\section{Data Collection Instruments}

The study used structured questionnaires and interview guide in collecting primary data.

\section{Questionnaires}

The questions were based on a 5-point Likert scale. The questionnaire would capture information on the variables and was divided into nine sections, A, B, C, D, E, F, G, H and I. Section A would capture general information of the respondents, section $\mathrm{B}$ would cover information on operational performance, section $\mathrm{C}$ would cover information on supply chain performance, D \& E would capture information on inventory categorization, part F \& G would cover information on demand forecasting, while part H \& I would cover information on Just-in-Time practice in Siaya County public hospitals.

\section{Interview Guide}

Interview with randomly selected respondents from sample size was used to compliment information derived from the questionnaire items. This was an enhancement to gather information that may not have otherwise been anticipated during the construction of the questionnaire.

\section{Data Collection Procedure}

Before proceeding to collect data, an introductory letter from Jaramogi Oginga Odinga University of Science and Technology was obtained to enable the researcher, get a NACOSTI permit to collect data from the field. The questionnaires would then be administered through a pick and pick method to the respondents at their specific places of work. Follow up was done through mobile phone calls to remind respondents on agreed upon dates of collection of the instrument after which they were collected. The researcher would then organize to have group interview with different groups. Questionnaires would then be checked to find out whether they were appropriately and fully responded to before proceeding to do the analysis.

\section{Pilot Testing}

Pilot testing was conducted on staff of Kombewa sub county hospital across the 4 sections under study. It would help verify the effectiveness of the instruments and would give feedback that helps the researcher and measure the exact time required to complete all questions or identify any other problematic issues with the questionnaire format. Hill (1998) proposes 10 to 30 percent of the anticipated respondents to pilot the study in a survey research. For this study, 10 per cent of the anticipated respondents was used for piloting. This implies that 10 respondents from Kombewa SubCounty Hospital was randomly selected for purposes of pilot testing. After pilot testing of the instrument on the proposed number of people, the researcher would look at the pattern in the feedback, analyze the responses and use the data to revise the instrument.

\section{Validity Test}

Content validity was used to determine the validity index. The questionnaires were given to the two supervisors in the School of Business and Economics to evaluate and rate each item in relation to the objectives as "not relevant" or "relevant" on a scale of the 1-4 such that; $1=$ not relevant, $2=$ somehow relevant, 3 = relevant and $4=$ very relevant. Content validity index would then be determined from the supervisors' agreement scale as $\mathrm{K} / \mathrm{N}$, where $\mathrm{K}$ being the number of items marked 3 or 4 and $\mathrm{N}$ the total number of items assessed.

The rated finding was used to calculate content validity index (CVI) using the formula:

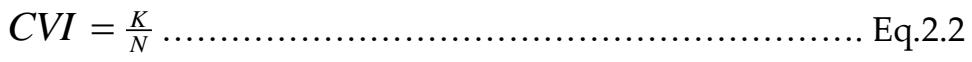


Where: $\mathrm{K}=$ Total number of items in the questionnaire declared valid by both experts; and $\mathrm{N}=$ Total number of items in the questionnaire. This was solved as follows:

$$
C V I=\frac{K}{N}=\frac{39}{48}=0.8125
$$

The computed instrument content validity index (CVI) was $\varepsilon=0.8125>\varepsilon=0.7$. The computed CVI was greater than the minimum acceptable index of 0.70 as recommended in the survey studies by Amin, (2005) hence the instrument was valid for the study.

\section{Reliability Test}

Reliability of the instrument was checked through split-half reliability coefficient test. The items in the questionnaire was divided into; odd items represented by " $x$ " and even items represented by " $y$ ". The scores from both halves would then be correlated. Usually, the internal consistency of a measurement scale is assessed by using Cronbach's co-efficient alpha (Cronbach 1951) which was calculated using Flanagan Formula shown in Eq. 2.3.

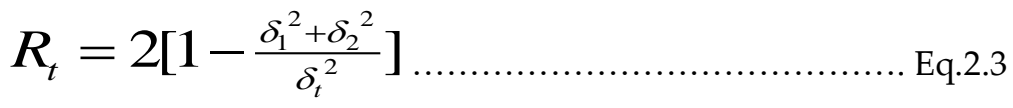

Where: $R_{t}=$ Reliability Coefficient of the Test; $\delta_{1}=$ Standard Deviation (S.D.) of Scores of $1^{\text {st }}$ Half; $\delta_{2}=$ Standard Deviation (S.D.) of Scores of $2^{\text {nd }}$ Half; and $\delta_{t}=$ Standard Deviation (S.D.) of Scores of Whole Tests

For overall analysis on reliability using Cronbach's alpha, the items analysed for this study were summed to create the different scores, which formed a scale on which Cronbach's alpha was computed. The computed Reliability Coefficient of the instrument was checked against the minimum acceptable index of 0.70 as recommended in the survey studies by Nunnally and Bernstein (1994). Reliabilities ranging from 0.5 to 0.60 are usually sufficient for exploratory studies (Nunnally \& Bernstein, 1994), while those in the range of 0.70 are acceptable and over 0.80 are good (Sekaran, 2003). The reliability obtained was as summarized in Table 3.

Table 3 Reliability Statistics

\begin{tabular}{lccc}
\hline Factor & No. of Items & $\begin{array}{c}\text { Cronbach's Alpha Based on } \\
\text { Un-Standardized Items }\end{array}$ & $\begin{array}{c}\text { Cronbach's Alpha Based } \\
\text { on Standardized Items }\end{array}$ \\
\hline Background & 03 & 0.987 & 0.983 \\
Inventory Categorization & 08 & 0.863 & 0.854 \\
Operational Performance & 08 & 0.819 & 0.805 \\
\hline Overall & 48 & 0.834 & 0.821 \\
\hline
\end{tabular}

Source: Survey Data, (2019).

The overall alpha for the items under investigation had a Cronbach's alpha of 0.834 indicating good internal consistency, while inventory categorization had an acceptable Cronbach's alpha coefficient of 0.863 , and lastly, operational performance had a good Cronbach's alpha coefficient of 0.819 . The minimum alpha for the items was 0.819 while the highest alpha was 0.987 both of which conformed to the project by George and Mallery (2003) thus the items formed a scale that had excellent internal consistency reliability. 


\section{Data Analysis}

Data was edited, classified, coded and keyed into the computer for analysis and summary of results presented with the help of Statistical Package for Social Sciences (SPSS, Version 24). SPSS has the capability of offering extensive data handling and numerous statistical analysis tools that can analyze from small to very large data statistics (Muijs, 2004). This study generated qualitative data and quantitative data. Qualitative data was analyzed using thematic and content analysis. Quantitative data was analyzed using both descriptive and inferential statistics. Descriptive statistics were analysed using graphical and numerical methods, measures of central tendencies like frequency percentage, mean, and standard deviation. Inferential statistics were analysed using regression and correlation analysis. Regression analysis provides an equation that describes the relationship between two variables while correlation analysis helps to determine the strength of linear relationship that is, how strongly associated the variables are (Mutai 2000). The analysis of variance (ANOVA) was checked to reveal the overall model significance. The individual regression coefficients were checked to see whether the independent variables (inventory management practices) affect operational performance of public hospitals in Siaya County. The hypothesis that guided the study was as follows:

Ho1: Inventory categorization has no statistically significant effect on operational performance of public hospitals in Siaya County.

The following regression model to establish the relationship between the study variables guided the study:

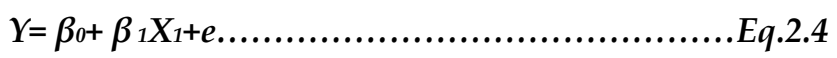

Where: $\mathrm{Y}=$ Operational Performance; $\mathrm{X}_{1}=$ Inventory Categorization Management Practice; $e$ - Error Term; $\beta_{0}$-represents the Model Constant; and $\beta_{1}$-are Regression Coefficients.

The regression model assumed independent, identical and normally distributed random variables with a zero mean and a constant variance at $5 \%$ significance level.

\section{Diagnostic Tests for Inferential Statistics}

Diagnostic Tests for Inferential Statistics was done using Exploratory Test for Normality and Multicollinearity Test. Exploratory data analysis was done using the numerical Kolmogorov-Smirnov Test to check for the normality of the data set. The correlation between independent variables were checked using Tolerance and Variance Inflation Factor (VIF) to ascertain multi-collinearity status.

\section{Results}

\section{Descriptive Statistics on Inventory Categorization}

Descriptive analysis was done on the effect of inventory categorization practice on operational performance. The results were summarized in Table 4 . 
Table 4 Descriptive Statistics for Inventory Categorization Practice and Operational Performance

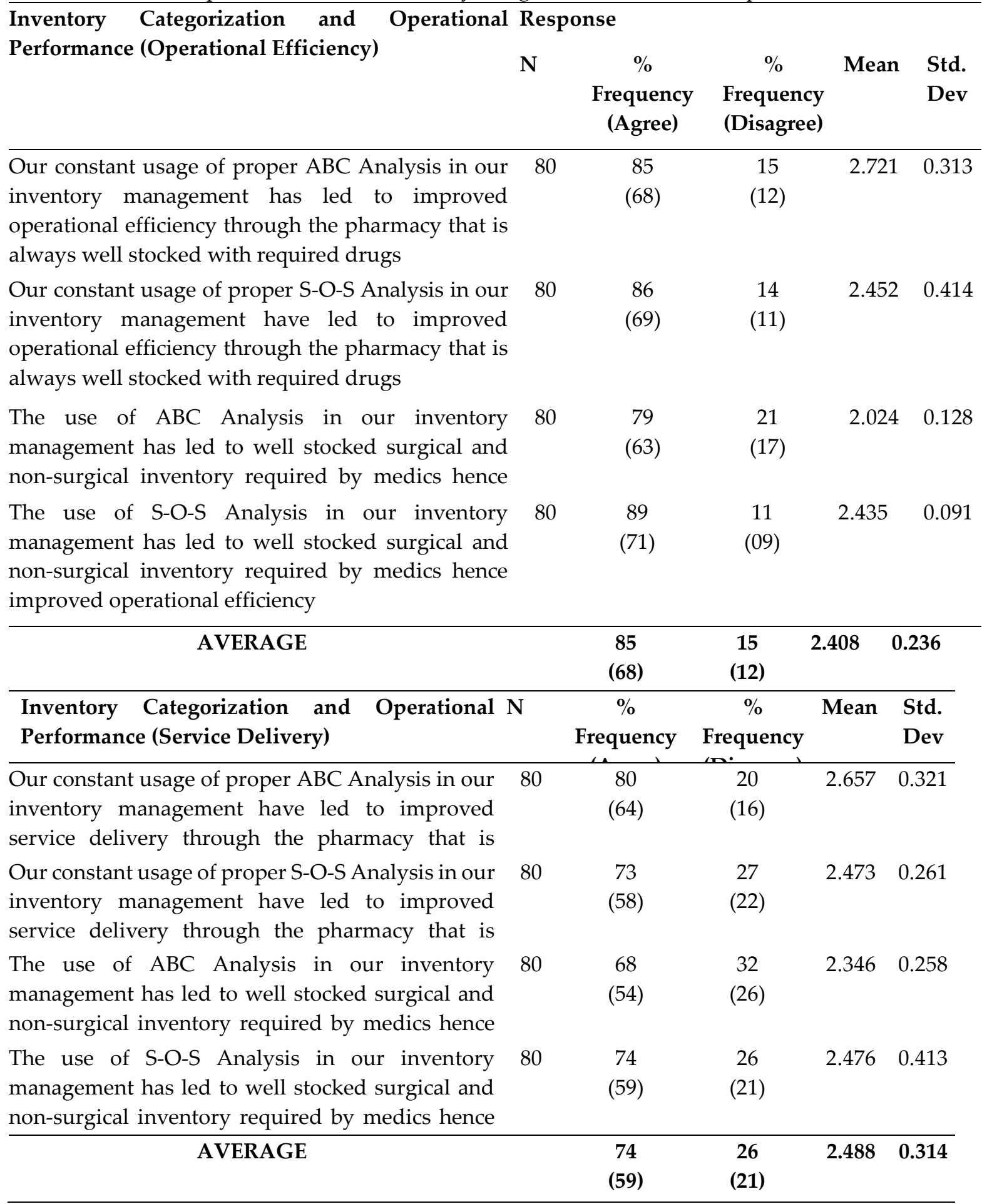

Source: Survey Data, (2019).

The study sought to investigate the effect of inventory categorization practice on operational performance of public hospitals in Siaya County. Table 4 shows that majority of Siaya County public 
hospitals believe that inventory categorization would have an effect on operational performance of public hospitals in Siaya County, with a mean response of 2.408 (for operational efficiency) within the range of $2.024 \leq \mu \leq 2.721$ at $85 \%(S . D=.236)$ and a mean response of 2.488 (for service delivery) within the range of $2.346 \leq \mu \leq 2.657$ at $74 \%(S . D=.314)$. This finding is consistent with the findings of John et al, (2015), Vipulesh (2015) and Wafula (2016). John et al (2015) in their study found out that most of the flour milling firms that adopted scientific inventory categorization practices experienced increased operational performance as compared to those that adopted manual practices. Vipushel (2015), found out that proper inventory classification improves the level of customer service which in turn improves financial performance. Wafula (2016) added that the use of ABC analysis in categorizing inventory have a positive increase on operational performance.

\section{Descriptive Statistics on Operational Performance}

Descriptive analysis was done on operational performance. The results were summarized in table 5 .

Table 5. Descriptive Statistics for Operational Performance

\begin{tabular}{|c|c|c|c|c|c|}
\hline Operational Performance (Operational Efficiency) & $\mathbf{N}$ & $\begin{array}{c}\% \\
\text { Frequency }\end{array}$ & $\begin{array}{l}\% \\
\text { Frequency }\end{array}$ & Mean & $\begin{array}{l}\text { Std. } \\
\text { Dev }\end{array}$ \\
\hline $\begin{array}{l}\text { The hospital always handles a large number of out- } \\
\text { patient's cases on daily basis }\end{array}$ & 80 & $\begin{array}{c}55 \\
(44)\end{array}$ & $\begin{array}{c}45 \\
(36)\end{array}$ & 2.933 & 1.216 \\
\hline $\begin{array}{l}\text { It takes the shortest time possible for patients to go } \\
\text { through the treatment process (for out-patient) }\end{array}$ & 80 & $\begin{array}{c}58 \\
(46)\end{array}$ & $\begin{array}{c}42 \\
(34)\end{array}$ & 2.628 & 1.137 \\
\hline $\begin{array}{l}\text { For the last two years the hospital has recorded } \\
\text { reduction in mortality rates }\end{array}$ & 80 & $\begin{array}{c}56 \\
(57)\end{array}$ & $\begin{array}{c}44 \\
(43)\end{array}$ & 2.917 & 1.313 \\
\hline $\begin{array}{l}\text { In-patients cases normally stay in the hospitals for a } \\
\text { shorter period before being discharged }\end{array}$ & 80 & $\begin{array}{c}51 \\
(41)\end{array}$ & $\begin{array}{c}49 \\
(39)\end{array}$ & 3.007 & 1.144 \\
\hline AVERAGE & & $\begin{array}{r}55 \\
(44)\end{array}$ & $\begin{array}{r}21 \\
(17)\end{array}$ & 2.871 & 1.203 \\
\hline Performance in Terms of Service Delivery & $\mathbf{N}$ & $\begin{array}{c}\% \\
\text { Frequency }\end{array}$ & $\begin{array}{c}\% \\
\text { Frequency }\end{array}$ & Mean & $\begin{array}{l}\text { Std. } \\
\text { Dev }\end{array}$ \\
\hline The suggestion box is easily accessible to patients & 80 & $\begin{array}{c}60 \\
(48)\end{array}$ & $\begin{array}{c}40 \\
(32)\end{array}$ & 3.726 & 1.321 \\
\hline $\begin{array}{l}\text { On average, patients are always satisfied with the } \\
\text { hospital services }\end{array}$ & 80 & $\begin{array}{c}51 \\
(41)\end{array}$ & $\begin{array}{c}49 \\
(39)\end{array}$ & 4.238 & 1.421 \\
\hline $\begin{array}{l}\text { Action is always taken on feedbacks from the } \\
\text { suggestion box }\end{array}$ & 80 & $\begin{array}{c}76 \\
(61)\end{array}$ & 24 & 2.416 & 1.232 \\
\hline $\begin{array}{l}\text { On average, patients do get the prescribed drugs in } \\
\text { the hospital pharmacy }\end{array}$ & 80 & $\begin{array}{l}87 \\
(70)\end{array}$ & $\begin{array}{c}13 \\
(10)\end{array}$ & 2.118 & 1.279 \\
\hline AVERAGE & & $\begin{array}{c}69 \\
(55)\end{array}$ & $\begin{array}{c}31 \\
(25)\end{array}$ & 3.125 & 1.313 \\
\hline
\end{tabular}

Source: Survey Data (2019) 
Table 5 shows that majority of Siaya County public hospitals believe that operational performance of public hospitals in Siaya County is good. Specifically, operational efficiency had a mean response of 2.871 within the range of $2.628 \leq \mu \leq 3.007$ at $55 \%$ ( $S . D=1.203$ ). This implies that $55 \%$ of the respondents in Siaya County public hospitals do agree that operational efficiency was considerably good. In addition, service delivery was also considerably good at a mean response of 2.522 within the range of $2.118 \leq \mu \leq 2.726$ at $69 \%$ (S.D $=1.313)$.

\section{Inferential Statistics}

Hypothesis stated that there is no significant statistical effect of inventory categorization practice on operational performance of public hospitals in Siaya County. The effect of inventory categorization on operational performance of public hospitals in Siaya County was investigated through linear regression analysis using the model in equation 3.0:

$$
Y=\boldsymbol{\beta}_{0}+\boldsymbol{\beta}_{1} L_{1}+\varepsilon_{1}
$$

where $P$ is operational performance, while $\beta_{0}$ is the intercept (a constant), $\beta_{1}$, is the slope associated to the independent variables $L_{1}$, and $\varepsilon$ is the error term which is assumed to be independent, identical normally distributed random variable with a zero mean and a constant variance.

Table 6. Model Summary

\begin{tabular}{lllll}
\hline Model & $\mathbf{R}$ & $\mathbf{R}$ Square & Adjusted R Square & Std. Error of the Estimate \\
\hline 1 & .877 & .769 & .743 & .023 \\
\hline
\end{tabular}

Source: Survey Data (2019)

The Model Summary table 6 gives the R square (0.769) and Adjusted R square (0.743). Thus, in this model, inventory categorization is predicting $76.9 \%$ of the variance in operational performance of public hospitals in Siaya County. This leaves $23.1 \%$ of the variation in operational performance of public hospitals in Siaya County being explained by the error-term or other variables other than inventory categorization. This finding also indicated the model's goodness of fit as exemplified by the coefficient of determination value of $\left(\mathrm{R}^{2}\right.$ value) of 0.769 adjusted to of 0.743 . The standard error of the estimate, of 0.023 being a measure of standard deviation around the fitted line suggests that about $95 \%$ of the prediction error in operational performance of public hospitals in Siaya County is less than $\pm 1.96(0.023)=0.045$.

Table 7. ANOVA

\begin{tabular}{llllll}
\hline Model & df & F-Change & $\begin{array}{l}\text { Sig. } \\
\text { F-Change }\end{array}$ & $\begin{array}{l}\text { Durbin } \\
\text { Watson }\end{array}$ \\
\hline 1 & Regression & 1 & 9.653 & 0.001 & 1.761 \\
& $\begin{array}{l}\text { Residual } \\
\text { Total }\end{array}$ & 79 & & & \\
\hline
\end{tabular}

Source: Survey Data, (2019)

The ANOVA table 7. shows that the computed F statistic was 9.653, with an observed significance level ( $p$-value) of 0.001 which was also less than $p<0.05$. This shows that the significance can be extended to $99.99 \%$ confidence interval. The independence of residuals in this model was analysed using Durbin-Watson statistic. Considering a Durbin-Watson statistic of 1.761, it was deduced that there was no serial correlation of the residuals as the values were within the accepted threshold of between 1.5 to 2.5 as was recommended by Hayes, (2013). 
Table 8. Regression Coefficients of Inventory Categorization and Operational Performance

\begin{tabular}{|c|c|c|c|c|c|}
\hline Model & $\begin{array}{r}\text { Unst } \\
\text { Co }\end{array}$ & $\begin{array}{l}\text { dardized } \\
\text { icients } \\
\text { Std. Er. }\end{array}$ & $\begin{array}{c}\text { Stand. Coef. } \\
\text { Beta }\end{array}$ & $\mathrm{t}$ & Sig. \\
\hline 1(Constant) & 2.449 & 1.023 & & 2.394 & .000 \\
\hline Inventory Categorization & .754 & .217 & .537 & 3.475 & .002 \\
\hline $\mathbf{R}$ & 0.877 & & & & \\
\hline R-squared & 0.769 & & & & \\
\hline Adjusted R-squared & 0.743 & & & & \\
\hline F-statistics & 9.653 & & & & \\
\hline Prob. (F-statistics) & 0.001 & & & & \\
\hline
\end{tabular}

Source: Survey Data, (2019).

Considering hypothesis which stated that there is no significant statistical effect of inventory categorization practice on operational performance of public hospitals in Siaya County, the findings indicate that there was a significant statistical effect of inventory categorization on operational performance $(\beta=.754 ; p<.05)$. The regression model thus indicates that a one-unit increase in inventory categorization would increase operational performance by 0.754 units in Siaya County public hospitals. The null hypothesis that there is no significant statistical effect of inventory categorization practice on operational performance of public hospitals in Siaya County was therefore rejected and the alternative hypothesis that there is a statistically significant effect of inventory categorization practice on operational performance of public hospitals in Siaya County was instead accepted. This affirms the position by John et. al., (2015) who established that most medium sized flour milling firms that used inventory categorization realized increased operational performance as compared to those that employed manual approaches. Vipulesh (2015) also added that, proper inventory categorization always improves operational efficiency, which in turn improves financial performance. Considering the manufacturing industry, Yazan (2017) found comparable results that inventory categorization have a positive impact on operational excellence on Jordanian Industrial factories. Yazan, (2017) further adds that categorizing inventory is currently considered as a backbone and a critical pillar for many companies who strive to achieve competitive advantage through operation. John (2016) also found out that there exists a significant relationship between inventory categorization and operational performance of public hospitals in Uganda. On the contrary, Suleman (2018) in Ghana however found that the performance of manufacturing firms did not depend on categorizing raw materials. Probably, this could be attributed to isolated cases of standardized operations where specific inventory is inputted. Mwajuma (2013) in Tanzania attests that inventory categorization by $\mathrm{ABC}$ analysis had a positive effect on operational performance of public hospitals.

Whereas there is general agreement save for one that inventory categorization would significantly improve operational performance, in Siaya County there were cases of non-compliance and so respondents had a number of observations to say regarding the general status of inventory categorization vi-a-vis operational performance of public hospitals. The respondents considered the whole process of inventory management right from budgeting, capitation, supplier payments and subsequent service delivery including but not limited to say: average length of stay for out-patients going through the treatment process, mortality rates, reduced stock-out, and reduced lead time.

A respondent quipped at one time that,

"Large ques would form in the morning as they open the hospitals but this would be served till patients are reduced to below five most of the time within very short time intervals" More so, when we organize 
our inventory system well, we find many patients being discharged on out-patient services with a few cases of admissions. Of course, at times the County Government has had financial challenges in times of delayed capitations from the Central Government. During such periods KEMSA debts end up not been settled in arrears and often they have suspended drug supplies till pending dues are paid thus rendering our service delivery at pains. Such times we find we have had very little to do but to turn our patients down against our service charter.

Another respondent added that,

"The resultant effect from interruptions of supplies by KEMSA would eventually lead to long ques at the service bays and subsequent high periodical mortality rates of patients which we regret. This shouldn't happen again. We often endeavor to attend to many patients averagely in a short time so as to save many lives."

Occasionally,

“...Our stores department has put all our inventories in specific categories so as to form various procurement lots and ease of control. This has been one reason that our operational efficiency has somehow improved..."

Njoroge (2015) do appreciate this fact that often times than not, Central Governments may delay to release capitation to various government agencies. This was imperative from the interviews with some of the respondents that Siaya has suffered delayed capitation from the Central Government. He however, appreciates that in times the capitations are released and other factors kept constant, inventory categorization has a significant effect on operational performance of public hospitals. In this case, that inventory management by categorization must be seen as a continuous process thus an organization should strive to manage its inventory portfolio through favorable categorization practices to reap good performance hence competitive advantage. This position is further supported by Wafula (2016) in his study on the effect of inventory categorization on operational performance of oil marketing companies in Kenya. Indeed, Njoroge (2015) sums it that the most popular inventory categorization practice commonly used is ABC analysis compared to SOS models. In as much as the inventory categorization techniques were used, the main challenge to its success was failure to invest in modern technologies, lack of top management training and unreliable suppliers.

\section{Summary of Findings}

Objective one sought to establish the effect of inventory categorization on operational performances of public hospitals in Siaya County. 85\% (Mean 2.408: $\mathrm{SD}=.236$ ) of the public hospital workers believe that inventory categorization influences the level of operational efficiency in public hospitals. $74 \%$ (Mean 2.488: $\mathrm{SD}=.314$ ) of the public hospital workers believe that inventory categorization influences the level of service delivery in public hospitals. Hypothesis stated that there is no significant statistical effect of inventory categorization practice on operational performance of public hospitals in Siaya County. This was rejected based on the findings which showed that inventory categorization had a statistically significant effect on performance of public hospitals in Siaya County with a coefficient of $\beta=.754$. This implies that when keeping the effects of Just-in-Time practices and demand forecasting constant, a unit increase in inventory categorization would increase operational performances of public hospitals in Siaya County by 0.754 units.

\section{Conclusion}

Objective one sought to establish the effect of inventory categorization on operational performances of public hospitals in Siaya County. The study finding indicated that inventory categorization has 
statistically significant effect on operational performances of public hospitals in Siaya County. From the findings obtained herein, it was concluded that the efforts a public hospital put in inventory categorization as an inventory management practice would eventually become critical in realizing an improved operational performance in terms of service delivery for the patients. Further to this, it was also evident that inventory categorization does not necessarily determine operational performance independently but rather in addition to other inventory management practices (demand forecasting and Just-in-time stock management).

\section{Recommendations}

Objective one sought to establish the effect of inventory categorization on Operational performances of Public hospitals in Siaya County. The study thus recommends that inventory managers should always categorize inventory in order of their respective value to the organization.

\section{References}

Aarti, D., \& Dhawal, M., (2013). Inventory Management Delivery Profits Through Stock Management. Journal of Economic \& Sustainable Development, 9(1). ISSN 222-1700.

Adam, M.G., (2008). The Motivational Effect of Personal Impact in Public Service: International Public Management Journal, 11(1).

Afnatu, D., \& Aseta, B., (2018). Impact of inventory Management Practices on firm's Competitiveness and Organizational Performance: Empirical Evidence from Micro and Small Enterprises in Ethiopia. Cogent Business and management Journal 5(1): 1503219

Amin, M., E., (2005). Social Science Sampling Methodology. Makerere University Construction Projects in Zambia. International Journal of Project Management, 27: 522-531.

Amin, M.E., (2005). Social Science Research Conception, Methodology and Analysis. Kampala, Makerere University Printery.

Asubonteng, P., McCleary, K.J. \& Swan, J.E., (1996). "SERVQUAL revisited: a critical review of service quality." Journal of Services Marketing, Vol. 10, No. 6, pp. 62-81.

Baki, B., Basfirinci, C.S., Cilingir, Z. \& Murat, A.R., (2009). An Application of Integrating SERVQUAL and Kano's Model in to QFD for Logistic Services: A Case Study from Turkey, 21(1), 106 -126

Birech, K.W., (2011). The Effect of Inventory management practices Strategy on the Performance of State Corporations in the Energy Sector in Kenya.

Bosua, R., \& Rens, S., (2007). Knowledge Sharing in Complex Organizational Environments. Electronic Journal of Knowledge Management \& Practice, 5(2).

Coyle, J.J.; Bardi, E.J. and Langley, J.C. (2003). The management of Business Logistics: A Supply Chain Perspective. Canada. Thomsom South-western.

Cronbach L. (1951). Coefficient alpha and the internal structure of tests. Psychomerika.16:297-334.

Dinesh, D., \& Choudary, Y.L., (2013). ABC Classification for Inventory Optimization. IOSR Journal of Business and Management, 15(1), pp. 38-41, ISSN: 2319-7668.

Gefen, D., (2002). Customer loyalty in e-commerce. Journal of the association for information systems, $3(1), 27-51$. 
Gliem, J. A., \& Gliem, R.R., (2003). Calculating, Interpreting, and Reporting Cronbach's Alpha Reliability Coefficient for Likert-Type Scales. In 2003 Midwest Research to Practice Conference in Adult, Continuing, and Community Education (pp. 82-88). The Ohio State, USA.

Gupta, S., \& Gupta, S. (2012). Effective Inventory Visibility-Its Impact on Profitability. International Indexed \& Referred Research Journal, 4 (39), 59-60

Isaksson, O. H. D. \& Seifert, R.W. (2014). Inventory leanness and the financial performance of firms. Production Planning \& Control: The Management of Operations, 25(12), 999-1014.

John C. O. (2016). Inventory management practices and the effectiveness of the supply chain of essential medicines in the public sector, Evidence from six selected public hospitals in Uganda. International Journal of science and Research (IJSR0 5(4): 1447-1456 April 2016.

John. N., Etim, J.J. \& Tommy, U. I., (2015). Inventory Management Practices and Operational Performance of Flour Milling Firms in Lagos, Nigeria. International Journal of Supply and Operations Management. 1(4): 392-406

Kaplan, R.S., \& Norton, D.P., (1992). The Balanced Scorecard; Measures that Drive Performance. Harvard Business Review, 70 (1): 71-79

Katz, N., Lazer, D. \& Nashir, C., (2014). Network Theory and Small Groups. Small Group Research, 35(3): 307-332.

Kenya National Bureau of Statistics (2018). Poverty Level in Kenya. Nairobi Printing Press.

Kobia, R.G., (2018). Effect of inventory management practices on operational performance of Government Hospitals in Kenya. International Journal of Management. Vol 7 N08 ISSN 21346450

Kothari, C. (2014). Research methodology: Methods and techniques, (2nd Ed). New Dehli: New Age International Publishers Ltd.

Kwadwo, B., (2015). The Impact of efficient inventory management on profitability: Evidence from selected manufacturing firms in Ghana. MPRA paper 67889.

Lavely, R., (1996). Can you profit from improved inventory control? Auto Inc Magazine, 44(3).

Lysons, K., \& Farrington, B., (2012). Purchasing and Supply Chain Management. London: Prentice Hall.

Miller, R., (2010). Inventors Control: Theory and Practice. New Jersey: Prentice Hall.

Ministry of Health (2018). Annual Report on Disease Prevalence in Kenya

Mugenda, O.M. \& Mugenda, A.G., (2003). Research Methods. Acts Press.

Mwajuma, K., (2013). An assessment of effectiveness of inventory control system in the public sector in Tanzania a case of Kilwa District council: International Journal of Business and management. ISSN 2415-5643 vol 5 issue 456

Neely, A.D. (2005). The Evolution of Performance Measurement Research: Developments in the last Decade and a Research Agenda for the next". International Journal of Operations and Production Management, 25(12), 1264-77. 
Njoroge, W.M., (2015). Inventory Management Practices and Performance of Public Hospitals in Kenya. The International Journal of Logistics Management, 12(1): 1-19

Olema, H. Supply chain performance practices and SMEs performance in Arua municipality Uganda. International Journal of Business management and strategy. ISSN 2157-6068 $2018 \mathrm{vol}$ 10, No 2.

Omolo, O. V., Mwithiga, W.M., Chepkulei, B., \& Raymond, M.M. (2015). Role of Inventory Management Practices on Performance of Production Department. A Case of Manufacturing Firms. International Journal of Economics, Commerce \& Management, 3(5), ISSN 2348-0386.

Otundo, B.J., \& Okibo B. W., (2015). The Effect of Inventory Management Practices on Operational Performance in Kisii County Government, Kenya. International Journal of Social Sciences and Information Technology, 1(4), ISSN 2412-0294

Penrose, E., (1959). Contributions to the resource-based view of strategic management. Journal of Management Studies, 44(1), 2322-2380.

Porter, M., (1985). Advanced Competitive Advantage. Journal of Inanity, 16(3):256-273.

Powell, C.T., (2011). Neuro-strategy: Strategic Management Journal, 32(13):1484-1499.

Raeeda J.A, Yara, K.A.T., Mais E.A \& Rasmi A. (2017). Effect of Supply Chain Management Dimensions on Health Care Service Quality on Jordanian Private Hospitals. International Journal of Management and Strategy. Vol 4, No 3 ISSN 19233965

Rotimi, A.G., Bochie-Mensah, O. F \& Olubimmi F. O. (2016). Effect of Supply Chain Management on Performance in Selected Private Hospitals in Ilorin, Nigeria. International Journal of Economics Behavior, 7(1): 99-116.

Sekaran, U., (2006). Research Methods for Business: A Skill Building Approach. $4^{\text {th }}$ edition. New Jersey: John Wiley and Sons, Inc.

Stan, W., \& Karan, F., (2004). Analysis Methods \& Applications. Social Network International Journal of Business and Social Science, 5(2).

Stevenson, B., (2010). Operations Management, (10 th $e d$.$) . New York: McGraw Hill Publishing.$

Suleman B, (2018). Impact of inventory management on firm performance: A case study of selected manufacturing firms in Ghana. International Journal of Finance and Accounting. ISSN 21684812. 2018, 7(4): 83-96

Vipushel, S., (2015). Impact of Inventory Management on the Financial Performance of the firm. IOSR Journal of business and management (IOSR-JBM), 17(4): 01-12

Wafula, A.M., (2016). Inventory Management and Operational Performance of Oil Marketing Companies in Kenya.

Waithaka, S.W., (2015). Inventory Management Systems and Supply Chain Performance in Public Hospitals in Nairobi Kenya.

www.google.com/Kenya Open Data

www.google.com/Siaya.go.ke

Yamane, Y., (1967). Statistics: An Introductory Analysis, (2nd Ed.), New York: Harper and Row. 